\title{
A Preliminary Spectroscopic Approach to Evaluate the Effectiveness of Water- and Silicone-Based Cleaning Methods on Historical Varnished Brass
}

\author{
Michela Albano ${ }^{1,2}$, Silvia Grassi ${ }^{3}{ }^{\circledR}$, Giacomo Fiocco ${ }^{1,4}$, Claudia Invernizzi ${ }^{1,5}{ }^{\circ}$, \\ Tommaso Rovetta ${ }^{1}\left(\mathbb{D}\right.$, Maurizio Licchelli ${ }^{1,6}{ }^{\mathbb{D}}$, Raffaella Marotti ${ }^{7}$, Curzio Merlo ${ }^{1,8}$, \\ Daniela Comelli $^{2}$ and Marco Malagodi ${ }^{1,9, *}$ \\ 1 CISRiC, Arvedi Laboratory of non-Invasive Diagnostics, University of Pavia, 26100 Cremona, Italy; \\ michela.albano@unipv.it (M.A.); giacomo.fiocco@unipv.it (G.F.); claudia.invernizzi@unipv.it (C.I.); \\ tommaso.rovetta@unipv.it (T.R.); maurizio.licchelli@unipv.it (M.L.); curzio.merlo@unipv.it (C.M.) \\ 2 Department of Physics, Polytechnic of Milan, 20133 Milan, Italy; daniela.comelli@polimi.it \\ 3 Department of Food, Environmental, and Nutritional Sciences (DeFENS), University of Milan, 20133 Milan, \\ Italy; silvia.grassi@unimi.it \\ 4 Department of Chemistry, Università di Torino, Via Pietro Giuria 5, 10125 Torino, Italy Università di Torino, \\ 10125 Turin, Italy \\ 5 Department of Mathematical, Physical and Computer Sciences, University of Parma, 43124 Parma, Italy \\ 6 Department of Chemistry, University of Pavia, 27100 Pavia, Italy \\ 7 Department of Pure and Applied Sciences (DiSPeA), University of Urbino "Carlo Bo", 61029 Urbino, Italy; \\ raffaella.marotti@uniurb.it \\ 8 Laboratorio di Diagnostica applicata ai Beni Culturali di Cr.Forma, 26100 Cremona, Italy \\ 9 Department of Musicology and Cultural Heritage, University of Pavia, 26100 Cremona, Italy \\ * Correspondence: marco.malagodi@unipv.it; Tel.: +39-349-644-5217
}

Received: 12 May 2020; Accepted: 5 June 2020; Published: 8 June 2020

\begin{abstract}
Soiling deposition and wrong conservation practices are among the causes of the decay process that can affect the morphological, mechanical, and compositional features of the varnish, the most exposed layer of an artefact. In this perspective, the identification of the best cleaning practices is a priority. During the 18th century, scientific instruments of the highest quality were built, and peculiar varnishes were produced to confer protection and elegance to their metal elements. For this study, based on a historical recipe, we have reproduced a peculiar spirit varnish, enriched with natural resins and colorants, and we have applied on it a synthetic soiling mixture to simulate the aging conditions. We have then performed a non-invasive multi-analytical study to monitor the effectiveness of two water-based and a silicone-based, cleaning methods, namely, water in agarose, Tween $20(3 \%)$ in agarose, and Velvesil ${ }^{\mathrm{TM}}$ Plus. The study includes colorimetry, Fourier transform infrared (FTIR) spectroscopy and X-ray fluorescence (XRF) mapping, coupled with chemometrics. Principal component analysis applied to FTIR spectral data has been demonstrated to be a powerful tool to enhance weak variations in the IR spectra, empowering the interpretation of cleaning effect versus the application time of each cleaning test.
\end{abstract}

Keywords: FTIR spectroscopy; XRF mapping; colorimetry; PCA; varnished brass

\section{Introduction}

Historically, brass has always been employed for the metal components of scientific instruments due to its malleability and ductility, and to its golden aspect aimed to confer their elegance. Such a surface, in many artefacts, was protected and enriched by varnishes. The role of these varnish layers is crucial, representing part of the technological value of these objects. In fact, varnishes preserve the 
metal from the triggering of the corrosion in the alloy caused by environmental moisture, pollutants, and other decaying factors [1]. During the 18th century, the manufacturing of scientific instruments reached its apogee bearing to the use of peculiar materials and procedures that today make these objects a unique portion of the cultural heritage.

Varnish recipes are described in historical treatises and dictionaries [2]. Within the literature, the Swedish chemist Jons Jacob Berzelius (1779-1848) [3] was the first to recommend the protection of scientific instruments by an organic coating. Some recipes from his volume refer to a varnish made of natural resins and colorants, able to preserve and confer a shiny golden aspect to the surface. This varnish is described to have outstanding properties, very close to those of the precious Chinese lacquer made of the sap of the Rhus Verniciflua tree (Toxicodendron vernicifluum), brought to fame in Europe during the 18th century thanks to the Jesuit pilgrims' writings [4].

Nowadays, historical scientific instruments are preserved as cultural heritage objects, but in the past centuries they were used in the laboratories and their surfaces were exposed to soiling, aggressive cleaning, and hands sweat deposition. The preservation of this class of objects and their consideration as cultural heritage artifacts is recent and protocols are still not available neither for the restoration nor for the cleaning procedures.

To fill this gap of knowledge and to lead toward an aware preservation practice of these objects, it is necessary to perform experimental studies focused on the specific constituent materials of historical scientific instruments. While several publications deal with cleaning methods for polychrome surfaces [5-7], only a few of them regard the interaction between natural resins and cleaning methods [8].

As concerns the cleaning procedures, a first approach in the cultural heritage field started with a systematic development of aqueous methods carried out by Richard Wolbers in the 1980s of the 20th century $[9,10]$. As known, water can solubilize ionic compounds and some hydrophilic films, but its solvent power can be extended also to non-polar fractions. The water solvent power, in fact, can be modulated by adding, for instance, acids and bases, surfactants, or enzymes. Moreover, the addition of agarose increases the solution viscosity, producing the so-called rigid gels, which ensure a safe and controlled action on delimited areas [11]. The incessant improvement of this highly flexible method allows it to be the most powerful, safe, and adjustable tool [12,13]. It is widely employed, notwithstanding the huge variety of available methods and cleaning products [14-18].

Over recent decades, with the development of the ready-to-use industrial products, numerous cleaning procedures have been getting popular among the restorers. Above all, the silicone-based solvent ones [19]. They are known to be non-toxic, in a gel shape, and mainly suitable for water-sensitive surfaces and acrylic paint [20-22].

In this study, a non-invasive methodology, which includes colorimetry, and Fourier transform infrared (FTIR) and X-ray fluorescence (XRF) spectroscopies, was accomplished to investigate the effect of three cleaning methods widely used in the restoration practice. In the field of cultural heritage, colorimetric measurements are customarily used to evaluate the cleaning effectiveness [23,24] by checking the modification in chromatic feature of the surfaces; XRF spectroscopy proved to be powerful in disclosing the distribution of elements in low concentration [25]; and FTIR spectroscopy is often employed in all its different configurations mainly to monitor the molecular changes in the varnish caused by aging or interaction with the cleaning agents [26-30]. In this framework, the present paper aims to show and discuss the new insights obtained from the development of a previous preparatory study [31]. To this aim, deionized water in agarose gel, Tween 20 in 3\% deionized water solution supported in agarose gel, and the Velvesil ${ }^{\mathrm{TM}}$ Plus were selected as cleaning methods to be tested, for their different polarity and surfactant action. They were applied to soiled brass mock-ups coated by traditional protective materials.

Univariate and multivariate data analysis approaches were investigated to study the cleaning dynamics. With the goal of interpreting FTIR and colorimetric results with a multivariate perspective, principal component analysis (PCA) was considered to explore the cleaning dynamics and confirm- 
as well as clarify-the findings based on the univariate approach. Different studies witness the use of this unsupervised procedure to explore multivariate data in the cultural heritage field [32-36].

In Section 2, we will describe the materials and the procedures used to build up the mock-ups and the employed analytical approach. In the following Section 3, we will present and discuss the results achieved through the analytical approach. Finally, in the concluding section, we will summarize the main results about the cleaning test effectiveness and the applied methodology.

\section{Materials and Methods}

\subsection{Mock-Up and Varnish Preparation}

The mock-ups were obtained by applying a spirit-based varnish layer on a lamina of brass OT 63 UNI $4892 \mathrm{Cu} 63 \%-\mathrm{Zn} 37 \%(10 \times 5 \times 0.1 \mathrm{~cm})$. The varnish was formulated according to a historical recipe [3]: shellac (Bresciani. Milan, Italy, Art.55881 28.35 g), sandarac (Bresciani., Milan, Italy, Art.56143, 56.70 g), mastic (Bresciani., Milan, Italy, Art.56111, 28.35 g), elemi gum (Bresciani., Milan, Italy, Art.55812, 56.70 g), dragon's blood (Bresciani., Milan, Italy, Art.57491, 28.35g), gummi-gutta (Bresciani., Milan, Italy, Art.55851, 21.26 g), curcuma (21.26 g), saffron (12 grains), crushed glass $(85.10 \mathrm{~g})$, and ethanol 85\% (Girelli Alcool, Milan, Italy, $57.00 \mathrm{~g}$ ). The varnish was applied to the specimens using a soft brush. A specimen named $\mathrm{Tq}$-made up of metal and varnish-was kept as a benchmark. Three other specimens underwent a procedure to simulate the usage condition and the soiling deposition.

\subsection{Artificial Soiling and Sweat Deposition}

A soiling mixture made of two phases, dry and wet, was prepared according to existing protocols and experimentations [37]. The dry portion of the soiling mixture was composed of (i) sphagnum peat moss $(20.82 \% w / w)$, (ii) carbon black (Bresciani. Milan, Italy, Art.60609, 1.92\% w/w), (iii) iron oxide (Bresciani. Milan, Italy, burnt sienna pigment, Art.60603, 0.55\% w/w), (iv) gelatin $(10.41 \% w / w)$, (v) soluble starch (Bresciani. Milan, Italy, Art.51761, 10.41\% w/w), (vi) Portland type I cement $(18.63 \% w / w)$, (vii) silica gel (Bresciani. Milan, Italy, Art.57592, 1.92\% w/w), (viii) lime (Bresciani. Milan, Italy, Art.52791, 16.71\% w/w), and (ix) kaolin (Bresciani. Milan, Italy, Art.52861, 18.63\%w/w). The wet portion of the mixture consisted of (i) high-grade mineral paraffinic oil $(0.8 \mathrm{~mL})$ and (ii) chloroform (99\% pure $\mathrm{CHCl}_{3}$, Sigma-Aldrich St. Louis, Missouri, USA, $19.1 \mathrm{~mL}$ ). Accordingly, $1.1 \mathrm{~g}$ of the dry mixture was mixed with $20 \mathrm{~mL}$ solution of oil in chloroform $(4.5 \% v / v)$; thus, forming a $3 \% w / v$ heterogeneous 2-phase suspension [8]. The mixture was applied by a soft brush on the specimen surfaces, covering at least half of the surface. A second coat was applied after ca. $30 \mathrm{~min}$.

Synthetic sweat was sprayed on samples to simulate the contact with the instrument user. The synthetic sweat was chosen according to DIN ISO 9022-12 to imitate human hand sweat with a pH of 2.3 (Synthetic Urine e.K., Eberdingen, Germany).

Each specimen displayed different treatments on their surface, as shown in Figure 1a-c: the soiled area (S), the sweaty one (Sw), the area where both soiling and sweat were present (SSw), and the area where the only varnish was applied (V). 
(a)

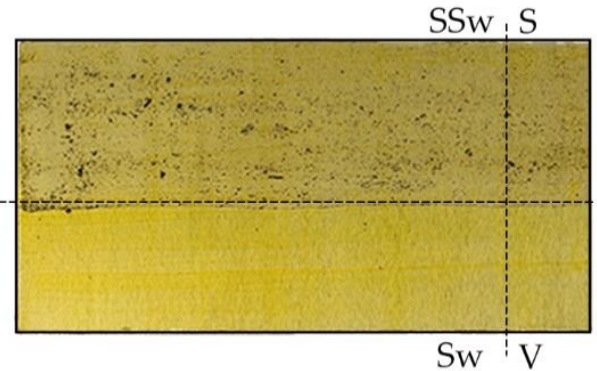

(b)

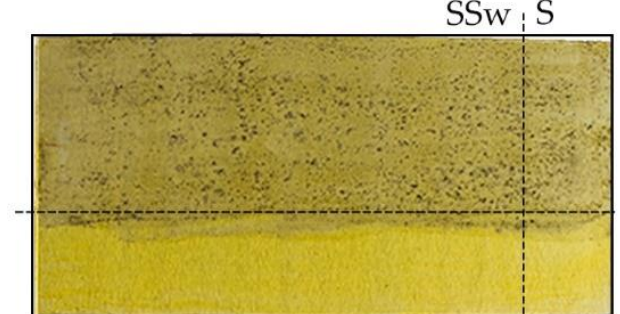

(c)

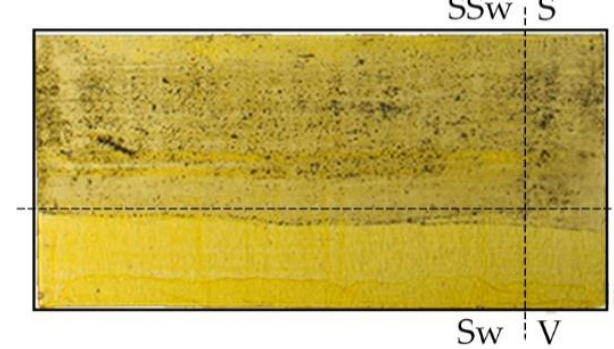

(d)

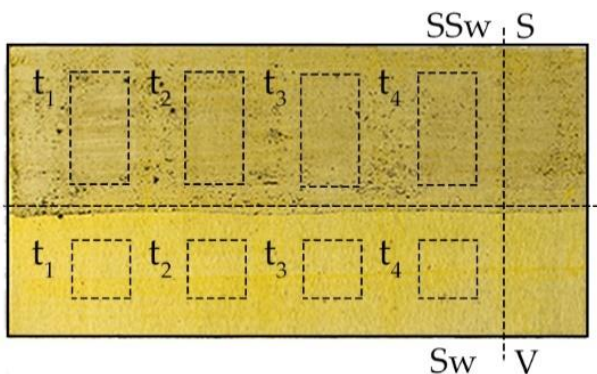

(e)

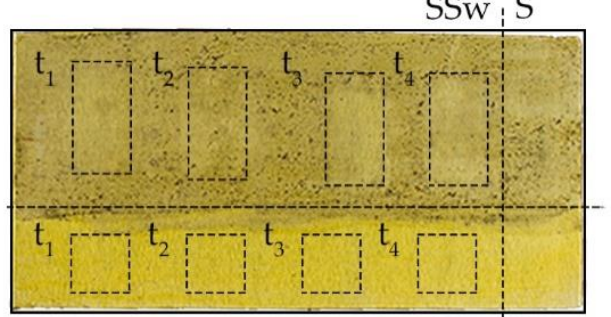

Sw $: \mathrm{V}$

(f)

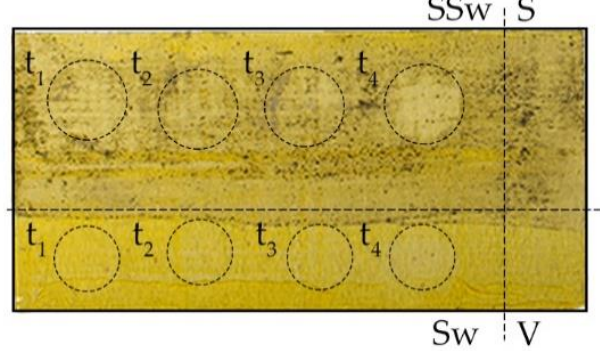

Figure 1. Photographic documentationck-ups, before (left) and after (right) the cleaning tests, respectively: water in agarose $(\mathbf{a}, \mathbf{d})$, Tween $20(\mathbf{b}, \mathbf{e})$, and Velvesil ${ }^{\mathrm{TM}}$ Plus $(\mathbf{c}, \mathbf{f})$. Treated areas and test distribution for each application time are schematically highlighted.

\subsection{Cleaning Tests}

Three cleaning tests were carried out on the SSw and Sw areas. They were selected among the most used agarose-based rigid gels and silicone-based methods: (i) deionized water in agarose gel (agarose: $0.75 \mathrm{~g}, \mathrm{H}_{2} \mathrm{O} 48 \mathrm{~mL}$ [38]), (ii) Tween 20 (Honeywell Fluka ${ }^{\mathrm{TM}}$ Fisher Scientific Italia, Rodano Milan, Italy) 3\% deionized water solution supported in agarose gel (agarose: $0.75 \mathrm{~g}$, Tween $201.5 \mathrm{~mL}$, $\mathrm{H}_{2} \mathrm{O} 48 \mathrm{~mL}$ [38]), and (iii) Velvesil ${ }^{\mathrm{TM}}$ Plus added with its solvent Cyclomethicone D5. Velvesil ${ }^{\mathrm{TM}}$ Plus (Momentive Performance Materials, Inc., Waterford, NY, USA) consists of a silicone copolymer gel and a silicone-based surfactant in a silicone-based solvent [19]. For each cleaning method four application times were considered according to the recommended cleaning practice. The following application times were selected: $t_{1}=30, t_{2}=60, t_{3}=90, t_{4}=180 \mathrm{~min}$ for the water in agarose; $t_{1}=45, t_{2}=60$, $t_{3}=90, t_{4}=180 \mathrm{~min}$ for the Tween $20(3 \%)$; and $t_{1}=5, t_{2}=15, t_{3}=25, t_{4}=45$ min for the Velvesil ${ }^{\mathrm{TM}}$ Plus. The Velvesil TM Plus was applied for shorter times due to its faster action compared to the other considered procedures. When $\mathrm{t}_{0}$ is reported in the text, it is referred to the surface condition before the tests, namely the sweaty (Sw), and sweaty and soiled (SSw).

The cleaning tests were applied along a line from the left to the right with an ascending order of application time, respectively for the SSw and the Sw areas. The shape of the test areas depended on the viscosity of the cleaning product: the agarose gels were applied in a rectangular shape $2 \times 1 \mathrm{~cm}$ sized in the SSw area and in a square shape $1 \times 1 \mathrm{~cm}$ sized in the Sw area, whereas the Velvesil ${ }^{\mathrm{TM}}$ Plus was spread in a round of $1.5 \mathrm{~cm}$ of diameter or less. In order to facilitate the reading of the results, the test areas are highlighted for each specimen in Figure $1 \mathrm{~d}-\mathrm{f}$ in which a change is recognizable in the delimitated cleaned areas with respect to the surfaces represented on Figure 1a-c. 


\subsection{Non-Invasive Analytical Investigation and Data Analysis}

A multi-analytical non-invasive approach was used to estimate the efficiency of each cleaning test in the removal of the artificial soiling.

Photographic documentation under visible light was acquired with a Nikon D4 full-frame digital camera equipped with a $50 \mathrm{~mm}$ f.1.4 Nikkor objective using a Softbox LED lamp. Colorimetric measurements were accomplished using a portable Konica Minolta CM-2600d spectrophotometer (Chiyoda, Tokyo, Japan). The average of the SCE values was considered (10 repetitions in the SSw and $\mathrm{Sw}$ area before and after the application of the treatments, and 3 repetitions after cleaning in the tested area for each time of application), and the dataset was processed in the CIELab space (CIELAB 1976). The chromatic difference (expressed as $\Delta E^{*}$ ) between the SSw and the Sw surfaces, and the corresponding cleaned ones, were considered. Moreover, $L^{*}$ difference $\left(\Delta \mathrm{L}^{*}\right)$ values were used to evaluate the darkening and the bleaching of the surface due to the removal of black particles in the soiling mixture. Furthermore, the colorimetric parameters $\left(\mathrm{L}^{*}, \mathrm{a}^{*}\right.$, and $\left.\mathrm{b}^{*}\right)$ were auto scaled and the dataset $3 \times 192$ (variables $\times$ objects) was explored by PCA. A differential value ( $\triangle \mathrm{PC} 1$ and $\triangle \mathrm{PC} 2$ scores) was calculated subtracting the score values of the cleaned areas during the time from the respective soiled area or soiled and sweaty one. Those differential values were used to study the behavior of the chromatic features depending on the application time of each cleaning method.

The portable ELIO XRF spectrometer produced by XGLab (Milano, Italy) with Rh anode was employed to collect XRF maps on the specimen surface ( $40 \mathrm{kV}, 15 \mu \mathrm{A}, 3 \mathrm{~s}$ per spectrum). The elemental distribution was pointed out by heat maps before and after the cleaning procedure. $\mathrm{Ca}$, as part of the dry fraction of the soiling mixture, was considered a marker for the soiling presence/removal, and Si distribution was also taken into account to determine any residue of Velvesil ${ }^{\mathrm{TM}}$ Plus. No marker elements were detected in the sweaty area; in this case, in fact, the technique was slightly informative.

Transflection mode FTIR spectra were recorded with the Alpha portable spectrometer (Billerica, MA, USA) equipped with R-Alpha module. Spectra were collected between $7500 \mathrm{~cm}^{-1}$ and $400 \mathrm{~cm}^{-1}$ at the resolution of $4 \mathrm{~cm}^{-1}$ with an acquisition time of $1 \mathrm{~min}$. The beam diameter measured $5 \mathrm{~mm}$. Each spectrum resulted from the average of the three measurements in the same area, in order to assess the analytical reproducibility. The selected dataset employed for the processing consisted of 36 spectra collected in the central point of the areas previously described and corresponding to the different treatments: two points in V, one in SSw and one in Sw; four points in SSw; and four in Sw, respectively for each cleaning application time. Data were processed in OPUS 7.2 software (Billerica, MA, USA). In this study, diagnostic bands were identified for the inorganic fraction of the soiling mixture, mainly ascribable to the Portland cement $\left(\mathrm{CaO} 61-67 \%, \mathrm{SiO}_{2} 19-23 \%, \mathrm{Al}_{2} \mathrm{O}_{3} 2.5-6 \%\right.$, $\mathrm{Fe}_{2} \mathrm{O}_{3} \quad 0-6 \%$, and $\mathrm{SO}_{3} 1.5-4.5 \%$ ) and the mineral kaolin. Variation in the absorbance intensity of the inorganic fraction bands was considered to evaluate the soiling removal. Moreover, diagnostic bands of the Velvesil ${ }^{\mathrm{TM}}$ Plus were identified and considered for the detection of the cleaning residues. FTIR spectra were reduced in the range $1800-490 \mathrm{~cm}^{-1}$ ( 36 objects $\times 702$ variables) and transformed by smoothing (Savitzky-Golay, 3 wavelengths gap size) and mean center to be explored by PCA. Each cleaning method was investigated by independent scores plot to enable a clear understanding of each trajectory or behavior. Starting from the diagnostic bands, the loadings allowed us to explain what affects the distribution of the data had along the considered PC, hence suggesting hypothesis about the factors responsible for the cleaning tests effectiveness. All the multivariate data analysis was performed in Matlab environment (v. 2016a, Mathworks, Inc., Natick, MA, USA) using the PLS toolbox (ver. 8.5, Eigenvector Research, Inc., Manson, WA, USA) software package.

The whole analytical campaign was carried out for each step of the mock-up preparation respectively, before and after the varnishing, the soiling, and the sweat application, and after the cleaning tests. 


\section{Results and Discussion}

In this paper, the main results are discussed and organized by analytical techniques in three subsections: (Section 3.1) colorimetric investigation, (Section 3.2) XRF spectroscopy, and (Section 3.3) FTIR spectroscopy.

\subsection{Colorimetric Investigation}

As concerns the SSw area, the $\Delta \mathrm{E}$ values smoothly decreased $\left(\Delta \mathrm{E}^{*}{ }_{\mathrm{t} 1}=4.17\right)$ for the water in agarose cleaning test till approaching a value close to zero $\left(t_{3}\right)$. The values of the total color variation $\Delta \mathrm{E}^{*}$ are shown in Table 1 . After $180 \mathrm{~min}$, no differences with the soiled surface were detected. The poor effectiveness of the cleaning method inferred by the drop of $L^{*}$ value at $t_{1}$, confirmed a darkening of the surface, and also by the slight variation of $\mathrm{a}^{*}$ and $\mathrm{b}^{*}$ (Table 2 ).

Table 1. Total color variation $\left(\Delta \mathrm{E}^{*}\right)$ between the area where both soiling and sweat were present $(\mathrm{SSw}) /$ the sweaty area $(\mathrm{Sw})$ surfaces, and the corresponding cleaned surfaces at different application times $\left(t_{1}, t_{2}, t_{3}\right.$, and $\left.t_{4}\right)$.

\begin{tabular}{ccccc}
\hline & & Water in Agarose & Tween 20 & Velvesil $^{\text {TM }}$ Plus \\
\hline \multirow{4}{*}{ SSw } & $\mathrm{t}_{1}$ & 4.17 & 3.05 & 4.70 \\
& $\mathrm{t}_{2}$ & 1.55 & 2.30 & 2.37 \\
& $\mathrm{t}_{3}$ & 0.61 & 3.26 & 4.56 \\
& $\mathrm{t}_{4}$ & 1.12 & 3.82 & 5.29 \\
& $\mathrm{t}_{1}$ & 3.97 & 4.94 & 8.41 \\
$\mathrm{~S} w$ & $\mathrm{t}_{2}$ & 3.83 & 5.47 & 10.30 \\
& $\mathrm{t}_{3}$ & 3.67 & 5.54 & 12.63 \\
& $\mathrm{t}_{4}$ & 4.81 & 6.55 & 16.95 \\
\hline
\end{tabular}

Table 2. Color coordinates $L^{*}, a^{*}$, and $b^{*}$ measured before $\left(t_{0}\right)$, and after the cleaning tests $\left(t_{1}, t_{2}, t_{3}\right.$, and $\left.t_{4}\right)$.

\begin{tabular}{|c|c|c|c|c|c|c|c|c|c|c|}
\hline & & \multicolumn{3}{|c|}{ Water in Agarose } & \multicolumn{3}{|c|}{ Tween 20 in Agarose } & \multicolumn{3}{|c|}{ Velvesil $^{\mathrm{TM}}$ Plus } \\
\hline & & $\mathbf{L}^{*}$ & $a^{*}$ & $\mathbf{b}^{*}$ & $\mathbf{L}^{*}$ & $a^{*}$ & $\mathbf{b}^{*}$ & $\mathbf{L}^{*}$ & $a^{*}$ & $\mathbf{b}^{*}$ \\
\hline \multirow{5}{*}{ SSw } & $\mathrm{t}_{0}$ & $\begin{array}{c}65.04 \pm \\
1.18\end{array}$ & $\begin{array}{c}2.22 \pm \\
0.14\end{array}$ & $\begin{array}{c}40.65 \pm \\
1.30\end{array}$ & $\begin{array}{c}61.54 \pm \\
1.55\end{array}$ & $\begin{array}{c}2.43 \pm \\
0.19\end{array}$ & $\begin{array}{c}41.70 \pm \\
1.58\end{array}$ & $\begin{array}{c}61.55 \pm \\
2.37\end{array}$ & $\begin{array}{c}3.14 \pm \\
0.36\end{array}$ & $\begin{array}{c}42.82 \pm \\
3.04\end{array}$ \\
\hline & $t_{1}$ & $\begin{array}{c}62.48 \pm \\
0.65\end{array}$ & $\begin{array}{c}2.52 \pm \\
0.12\end{array}$ & $\begin{array}{c}37.37 \pm \\
0.17\end{array}$ & $\begin{array}{c}63.87 \pm \\
0.25\end{array}$ & $\begin{array}{c}2.62 \pm \\
0.16\end{array}$ & $\begin{array}{c}39.74 \pm \\
0.79\end{array}$ & $\begin{array}{c}64.20 \pm \\
0.25\end{array}$ & $\begin{array}{c}2.93 \pm \\
0.07\end{array}$ & $\begin{array}{c}38.94 \pm \\
0.24\end{array}$ \\
\hline & $\mathrm{t}_{2}$ & $\begin{array}{c}63.79 \pm \\
0.36\end{array}$ & $\begin{array}{c}2.60 \pm \\
0.05\end{array}$ & $\begin{array}{c}41.49 \pm \\
0.18\end{array}$ & $\begin{array}{c}63.52 \pm \\
0.40\end{array}$ & $\begin{array}{c}2.68 \pm \\
0.06\end{array}$ & $\begin{array}{c}40.56 \pm \\
0.21\end{array}$ & $\begin{array}{c}62.28 \pm \\
0.13\end{array}$ & $\begin{array}{c}3.05 \pm \\
0.02\end{array}$ & $\begin{array}{c}40.57 \pm \\
1.26\end{array}$ \\
\hline & $t_{3}$ & $\begin{array}{c}64.85 \pm \\
0.35\end{array}$ & $\begin{array}{c}2.45 \pm \\
0.023\end{array}$ & $\begin{array}{c}40.11 \pm \\
0.13\end{array}$ & $\begin{array}{c}64.64 \pm \\
0.06\end{array}$ & $\begin{array}{c}1.92 \pm \\
0.10\end{array}$ & $\begin{array}{c}40.84 \pm \\
0.52\end{array}$ & $\begin{array}{c}64.02 \pm \\
1.17\end{array}$ & $\begin{array}{c}2.99 \pm \\
0.25\end{array}$ & $\begin{array}{c}38.99 \pm \\
0.63\end{array}$ \\
\hline & $t_{4}$ & $\begin{array}{c}65.40 \pm \\
0.43\end{array}$ & $\begin{array}{c}2.64 \pm \\
0.04\end{array}$ & $\begin{array}{c}39.67 \pm \\
0.46\end{array}$ & $\begin{array}{c}64.35 \pm \\
0.97\end{array}$ & $\begin{array}{c}2.46 \pm \\
0.17\end{array}$ & $\begin{array}{c}39.11 \pm \\
0.34\end{array}$ & $\begin{array}{c}64.79 \pm \\
1.02\end{array}$ & $\begin{array}{c}2.44 \pm \\
0.20\end{array}$ & $\begin{array}{c}38.69 \pm \\
0.05\end{array}$ \\
\hline \multirow{5}{*}{ Sw } & $\mathrm{t}_{0}$ & $\begin{array}{c}64.81 \pm \\
0.58\end{array}$ & $\begin{array}{c}1.56 \pm \\
0.18\end{array}$ & $\begin{array}{c}50.78 \pm \\
2.75\end{array}$ & $\begin{array}{c}65.15 \pm \\
0.34\end{array}$ & $\begin{array}{c}1.56 \pm \\
0.15\end{array}$ & $\begin{array}{c}58.32 \pm \\
0.98\end{array}$ & $\begin{array}{c}64.21 \pm \\
0.40\end{array}$ & $\begin{array}{c}2.99 \pm \\
0.50\end{array}$ & $\begin{array}{c}58.15 \pm \\
2.82\end{array}$ \\
\hline & $\mathrm{t}_{1}$ & $\begin{array}{c}61.44 \pm \\
0.06\end{array}$ & $\begin{array}{c}1.44 \pm \\
0.15\end{array}$ & $\begin{array}{c}48.70 \pm \\
0.93\end{array}$ & $\begin{array}{c}62.25 \pm \\
0.29\end{array}$ & $\begin{array}{c}1.60 \pm \\
0.16\end{array}$ & $\begin{array}{c}54.33 \pm \\
1.04\end{array}$ & $\begin{array}{c}64.40 \pm \\
0.20\end{array}$ & $\begin{array}{c}2.05 \pm \\
0.06\end{array}$ & $\begin{array}{c}49.80 \pm \\
0.95\end{array}$ \\
\hline & $t_{2}$ & $\begin{array}{c}61.10 \pm \\
0.42\end{array}$ & $\begin{array}{c}1.64 \pm \\
0.14\end{array}$ & $\begin{array}{c}49.86 \pm \\
0.47\end{array}$ & $\begin{array}{c}61.80 \pm \\
0.29\end{array}$ & $\begin{array}{c}1.33 \pm \\
0.02\end{array}$ & $\begin{array}{c}54.01 \pm \\
0.04\end{array}$ & $\begin{array}{c}64.32 \pm \\
1.26\end{array}$ & $\begin{array}{c}2.12 \pm \\
0.20\end{array}$ & $\begin{array}{c}47.89 \pm \\
3.25\end{array}$ \\
\hline & $t_{3}$ & $\begin{array}{c}61.86 \pm \\
0.40\end{array}$ & $\begin{array}{c}1.56 \pm \\
0.10\end{array}$ & $\begin{array}{c}48.61 \pm \\
0.93\end{array}$ & $\begin{array}{c}61.73 \pm \\
0.22\end{array}$ & $\begin{array}{c}1.23 \pm \\
0.12\end{array}$ & $\begin{array}{c}53.97 \pm \\
0.56\end{array}$ & $\begin{array}{c}63.78 \pm \\
0.60\end{array}$ & $\begin{array}{c}2.25 \pm \\
0.02\end{array}$ & $\begin{array}{c}45.55 \pm \\
0.46\end{array}$ \\
\hline & $t_{4}$ & $\begin{array}{c}61.40 \pm \\
0.05\end{array}$ & $\begin{array}{c}1.72 \pm \\
0.03\end{array}$ & $\begin{array}{c}47.40 \pm \\
1.17\end{array}$ & $\begin{array}{c}62.64 \pm \\
0.39\end{array}$ & $\begin{array}{c}1.16 \pm \\
0.03\end{array}$ & $\begin{array}{c}52.29 \pm \\
0.40\end{array}$ & $\begin{array}{c}63.17 \pm \\
1.33\end{array}$ & $\begin{array}{c}2.77 \pm \\
0.03\end{array}$ & $\begin{array}{c}41.24 \pm \\
0.08\end{array}$ \\
\hline
\end{tabular}

This behavior could be due to the interaction between the water and the polar portion of the soiling mixture: the gel showed mild efficiency in drawing the particles that were widely spread instead of removed. The PCA results, expressed in differential PC scores vs. cleaning time (explaining 
$48.12 \%$ and $33.84 \%$ of the variance, respectively for the PC1 and the PC2) are displayed in Figure $2 \mathrm{a}$. Similar behavior was observed for the $\triangle \mathrm{PC}$ s referred to in the $\mathrm{Sw}$ area, except for $30 \mathrm{~min}$ of exposure, where an increase of the $\triangle \mathrm{PC}$ was observed (Figure $2 \mathrm{~b}$ ).

(a)

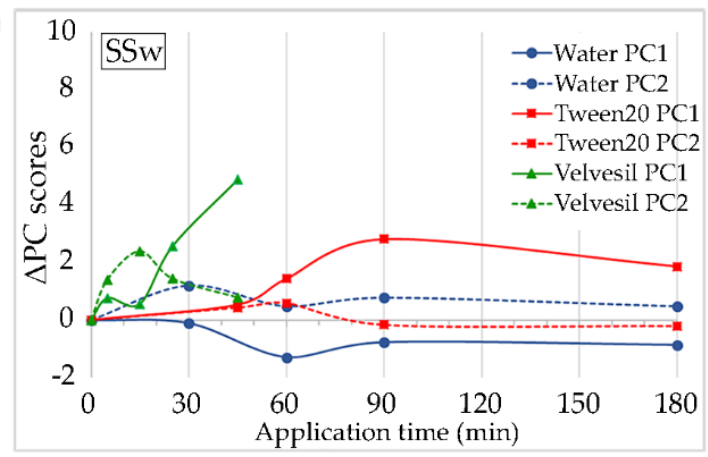

(b)

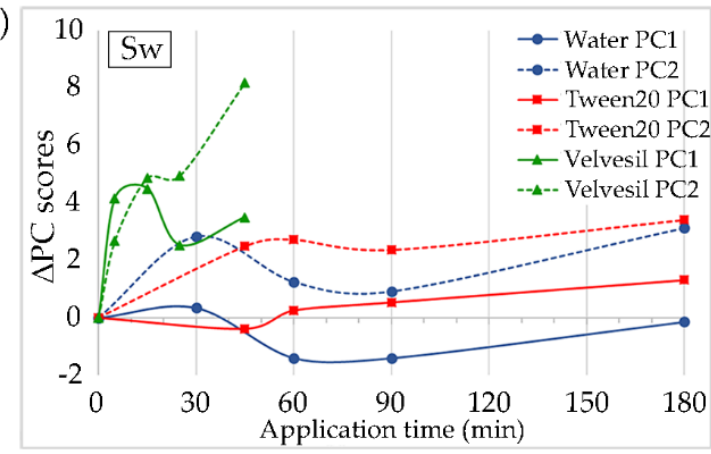

(c)

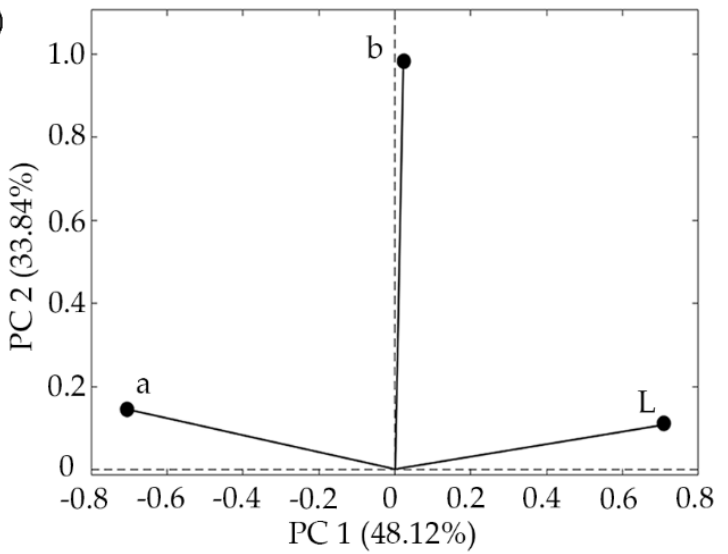

Figure 2. Principal component analysis (PCA) results on the colorimetric dataset expressed in differential PC scores vs. cleaning time for the three methods in the SSw (a) and Sw (b) area; in (c) the loadings are displayed.

An accurate reading of the loadings (Figure 2c) allowed us to explain these results: $\Delta \mathrm{PC} 1$ behavior was mainly driven by the $\mathrm{L}^{*}$ variability, whereas the $\triangle \mathrm{PC} 2$ was influenced by the $\mathrm{a}^{*}$ and $\mathrm{b}^{*}$ variability, with a higher influence by the latter. The hypothesis about the effect of the water in the agarose test was strengthened. In fact, $\triangle \mathrm{PC} 1$ and $\triangle \mathrm{PC} 2$ were characterized by a drop of around $60 \mathrm{~min}$, related to $\mathrm{L}^{*}$ and $\mathrm{b}^{*}$, confirming what was observed by $\Delta \mathrm{E}^{*}$ trends. There were no cases demonstrating the water in agarose cleaning effect. Indeed, the blue and light blue lines $(\triangle \mathrm{PC} 1$ and $\triangle \mathrm{PC} 2$ of the water in agarose test) did not rise back and exceed the starting point of the soiled dark surface.

As regards the Tween $20(3 \%)$ in agarose, it seemed to be more effective than the water in agarose in removing the dark matter: after cleaning, $\Delta \mathrm{E}^{*}$ in SSw area varied from $2.30\left(\mathrm{t}_{1}\right)$ up to $3.82\left(\mathrm{t}_{4}\right)$ and $\mathrm{L}^{*}$ grew $\left(\Delta \mathrm{L}^{*} \max =3.11\right.$ after $\left.90 \mathrm{~min}\right)$, signifying bleaching due to the removal of black particles, facilitated by the surfactant action of the solvent.

Observing the $\triangle \mathrm{PC}$ scores trend in Figure 2a, three phases are recognizable: in the first phase, i.e., within $45 \mathrm{~min}$, both $\triangle \mathrm{PC} 1$ and $\triangle \mathrm{PC} 2$ rose constantly; in the second phase, i.e., between 45 and $90 \mathrm{~min}$, a drop of $\triangle \mathrm{PC} 2$ was followed by a third phase described by a plateau. As a matter of fact, the second phase was the most effective one: $\mathrm{L}^{*}$ kept rising, showing a removal of the dark matter but a different action was observed for $b^{*}$ suggesting a change in the yellow tone.

This was confirmed by the loading investigation (Figure 2c) in which $\triangle \mathrm{PC} 1$ described $\mathrm{L}^{*}$ variability, whereas the $\triangle \mathrm{PC} 2$ was influenced by $\mathrm{a}^{*}$ and $\mathrm{b}^{*}$ coordinates. In the $\mathrm{Sw}$ area, $\Delta \mathrm{E}^{*}$ values varied from $4.94\left(\mathrm{t}_{1}\right)$ up to $6.55\left(\mathrm{t}_{4}\right)$ (Table 1$)$ : the variation was supported by the decreasing trend of $\mathrm{L}^{*}$ and $\mathrm{b}^{*}$, ascribable to an unexpected darkening and to a yellow component variation of the surface feature after 
the cleaning. $\triangle \mathrm{PC}$ score supported this variability suggesting also, in this case, that the major action was carried out between 45 and 60 min of application time (Figure $2 b$ ).

Concerning the Velvesil ${ }^{\mathrm{TM}}$ Plus cleaning test for the SSw area, $\Delta \mathrm{E}^{*}$ varied from 2.37 to 5.29 with an increasing trend since $t_{2}$. As in the Tween 20 test, $L^{*}$ resulted to be the parameter that most affected this variation $\left(\Delta \mathrm{L}^{*} \max\right.$ up to 3.24 after $45 \mathrm{~min}$ ) due to the dark layer removal and to the consequent surface bleaching. About $\mathrm{a}^{*}$ and $\mathrm{b}^{*}$, the variation of the latter was not negligible (Table 2) suggesting a modification of the yellow component. Additionally, in this case, the $\triangle \mathrm{PC}$ s scores endorsed these observations by displaying the presence of three different phenomena occurring in three different moments: in 5, in 15, and after $15 \mathrm{~min}$. In the first $5 \mathrm{~min}, \triangle \mathrm{PCs}$ described a rising of $\mathrm{L}^{*}$ that seemed to represent the best conditions for the dark matter removal. After $5 \mathrm{~min}$ a rise of $\triangle \mathrm{PC} 1$, respectively linked to a drop of $\triangle \mathrm{PC}$, could raise some doubts about the advantage of using a long application time of Velvesil ${ }^{\mathrm{TM}}$ Plus from the chromatic feature point of view.

The results obtained for $\mathrm{Sw}$ are as unexpected as those obtained for the Tween 20: the value of $\Delta \mathrm{E}^{*}$ varied from $8.41 \mathrm{up}$ to 16.95 . If combined with a substantial reduction in the $\mathrm{b}^{*}$ value $\left(\Delta \mathrm{b}^{*} \max =16.91\right.$ after $45 \mathrm{~min}$ ) that seemed to drag this trend, it could point to a change in the yellow component. This behavior is well described by the $\triangle \mathrm{PC}$ s scores (Figure $2 \mathrm{~b}$ ). The results of the Velvesil ${ }^{\mathrm{TM}}$ Plus test highlighted the strongest action. In fact, this highly non-polar and surfactant product seemed to interact also with the hydrophobic components of the sweat, probably inducing a transformation in the aesthetic properties of the surface.

\subsection{XRF Spectroscopy}

The spatial distribution of $\mathrm{Ca}$, obtained through XRF mapping, was used as the marker for the presence of the soiling layer and for its spatial distribution. The analysis showed that the three cleaning methods displayed a different degree of effectiveness in removing the soiling layer (Figure 3a-c). In detail, the use of water in agarose (Figure 3a) appeared not to be effective in Ca removal after 180 min: the slight differences in Ca amounts among the application times confirm the mild action carried out on the soiling.

(a)

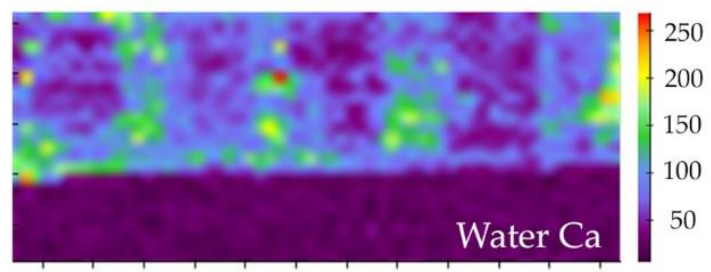

(b)

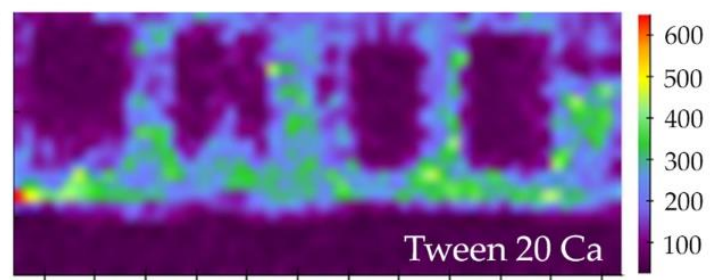

(c)

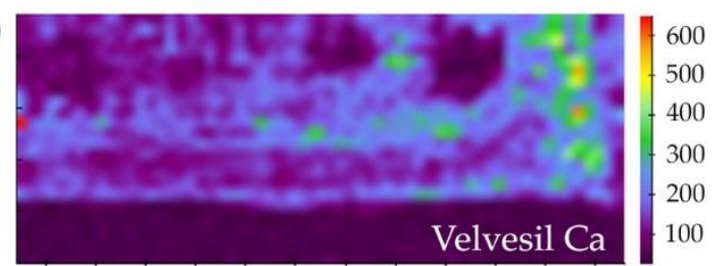

(d)

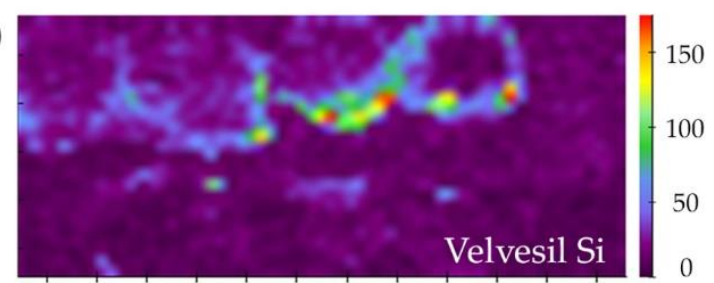

Figure 3. X-ray fluorescence (XRF) maps of the SSw area after the cleaning tests, respectively for water in agarose (a); Tween $20(\mathbf{b})$; Velvesil ${ }^{\mathrm{TM}}$ Plus where Ca distribution highlights the cleaned area (from $\mathrm{t}_{1}$ to $t_{4}$, from the left to the right) (c); and Si distribution revealed Velvesil ${ }^{\mathrm{TM}}$ Plus residues (d). The heat map colors represent the minimum (blue-violet) and the maximum (red) values.

Instead, when observing the XRF maps of the mock-ups cleaned by Tween 20 (3\%) (Figure 3b) and Velvesil ${ }^{\mathrm{TM}}$ Plus (Figure 3c), we note that $\mathrm{Ca}$ is never detected in the areas of the cleaning tests. In particular, for what concerns the Velvesil ${ }^{\mathrm{TM}}$ Plus (Figure 3c), the edges of the cleaning test areas are less defined than those of the Tween 20 tests. The removal of soiling is observed at $t_{1}$ and no trend during the time was noticed. 
As regards exclusively the Velvesil ${ }^{\mathrm{TM}}$ Plus method, a not negligible quantity of $\mathrm{Si}$ was detected on the cleaned surface: its distribution allowed us to monitor the cleaning residue, as shown in Figure $3 \mathrm{~d}$. These results confirm what was previously supposed based on colorimetric observations: water in agarose seemed to interact with the soiling, but with a low removal power, whereas Tween 20 and Velvesil ${ }^{\text {TM }}$ Plus were able to remove almost completely the soiling through their surfactant action. Moreover, by the XRF mapping, it was possible to highlight that the changes which occurred, were observed only in the area of the application of the cleaning test. It demonstrated that the interaction was limited to the areas where there was an effective contact between the cleaning products and the surface, and where the phenomena of absorption or binding were not detected. Nonetheless, it is worth noting that the selection of the cleaned area was more accurate in the case of the rigid gels (agar as support) with results more suitable for tiny and well-defined areas due to its stiffness. Contrarily, the silicone-based product seems to be unlikely to be accurately spread into the edges.

\subsection{FTIR Spectroscopy}

The high complexity of both soiling mixture and historical varnish, in terms of number and variety of constituents, makes the interpretation of the spectra complex. Nonetheless, thanks to the direct observations of the spectral signals and the PCA, relevant results were achieved, and some decisive information was gained, mainly about the Velvesil ${ }^{\text {TM }}$ Plus test.

The two bands of the Portland cement and kaolin inorganic fractions, with the absorbance maxima falling respectively at $533 \mathrm{~cm}^{-1}$ and $468 \mathrm{~cm}^{-1}$ (Figure 4), were identified as diagnostics of the cleaning effectiveness.

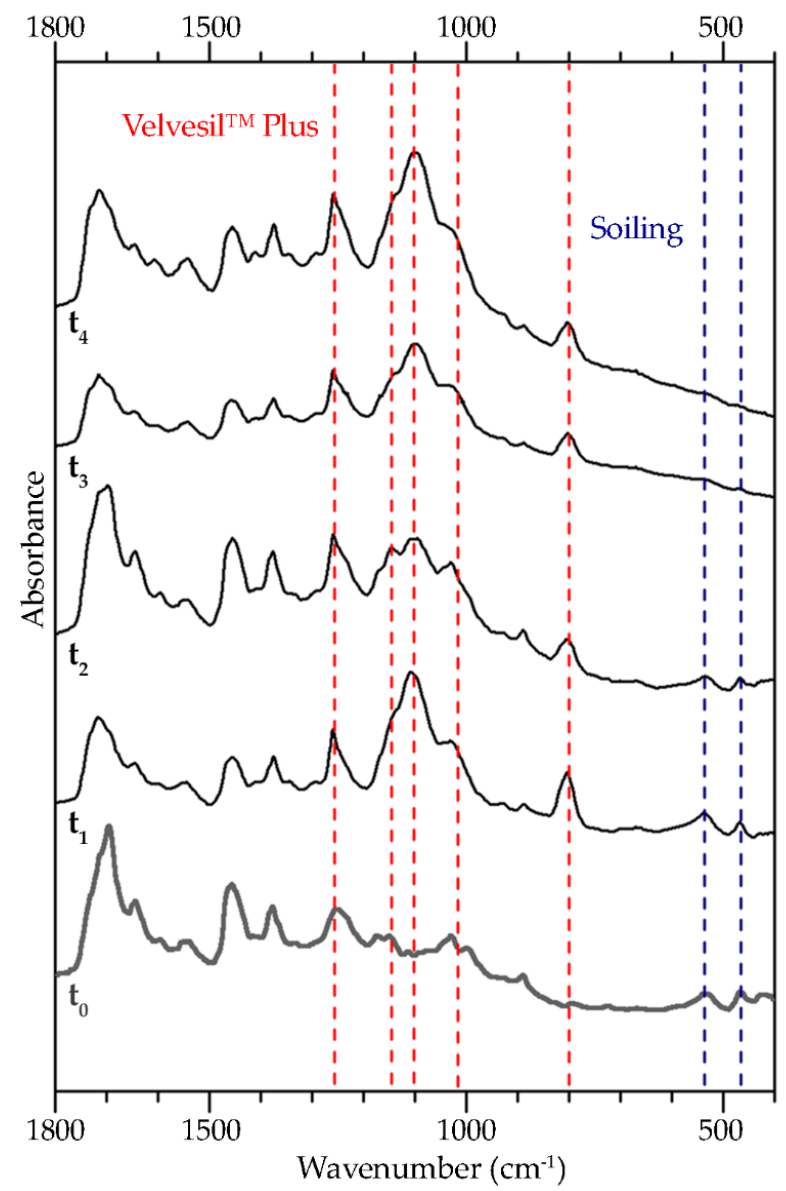

Figure 4. Fourier transform infrared (FTIR) spectra of the Velvesil ${ }^{\mathrm{TM}}$ Plus test from $\mathrm{t}_{0}$ (bottom grey line) to $t_{4}$ (top)-Velvesil ${ }^{\mathrm{TM}}$ Plus (red) and soiling mixture (blue) diagnostics bands are highlighted. 
The intensity reduction of these spectral features were able to provide quality information about the capability of the employed products to remove the soiling from the varnished surfaces. This reduction was clearly observed in the spectra collected in the Velvesil ${ }^{\mathrm{TM}}$ Plus test areas. They evidently showed a significant drop in the intensity, until disappearing, from $t_{0}$ to $t_{4}$, proving the positive cleaning effect of this cleaning procedure (Figure 4). However, FTIR spectroscopy analysis showed that the use of Velvesil ${ }^{\mathrm{TM}}$ Plus has some disadvantages to be taken into consideration in the art conservation field: after cleaning, residues of the product were detected on the surface, proved by the persistence of the silicone bands in the $1500-1000 \mathrm{~cm}^{-1}$ range and $800 \mathrm{~cm}^{-1}$. These hypotheses were corroborated by the results of the PCA shown in Figure 5a. The analysis explains a total of $88.73 \%$ variance by the first two components: $73.23 \%$ and $17.50 \%$ of the total variance, respectively for the PC1 and the PC2.

(a)

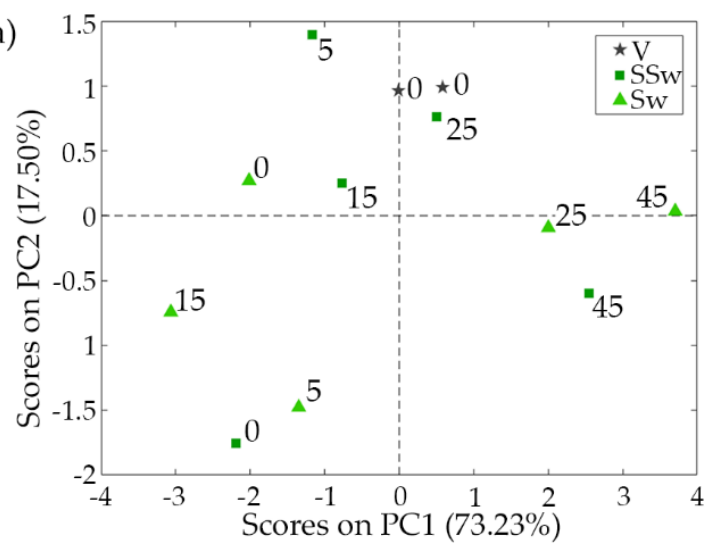

(c)

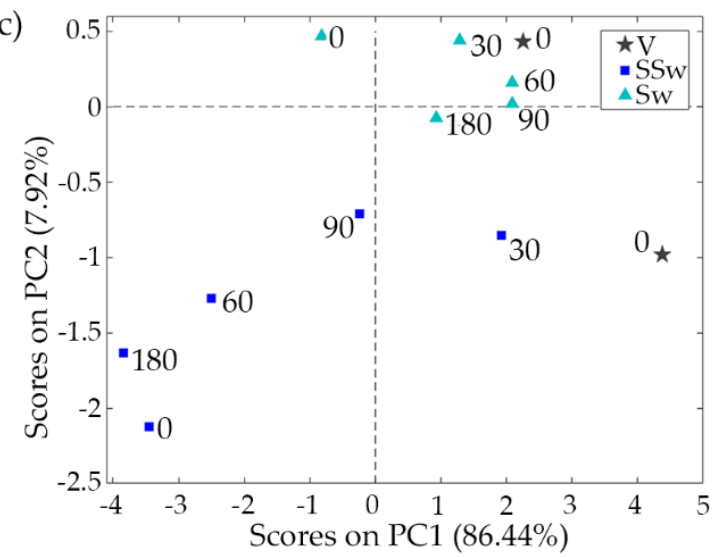

(e)

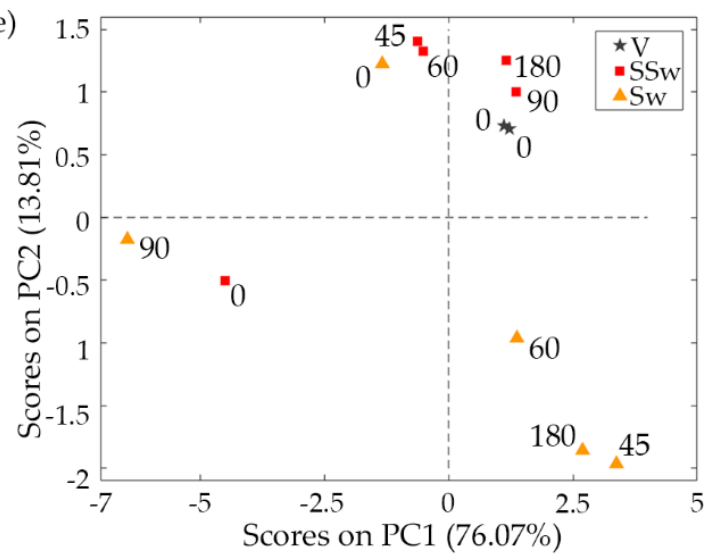

(b)

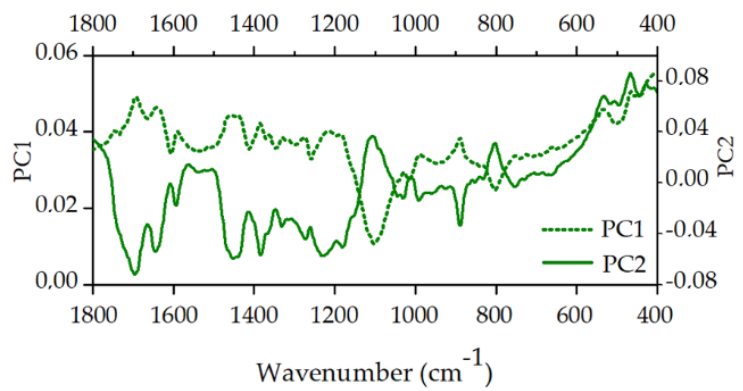

(d)

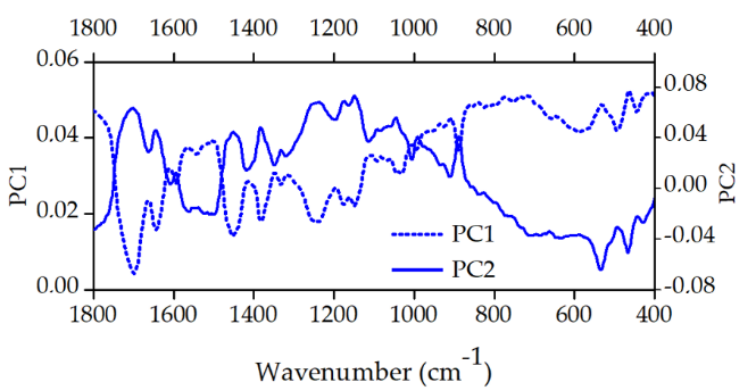

(f)

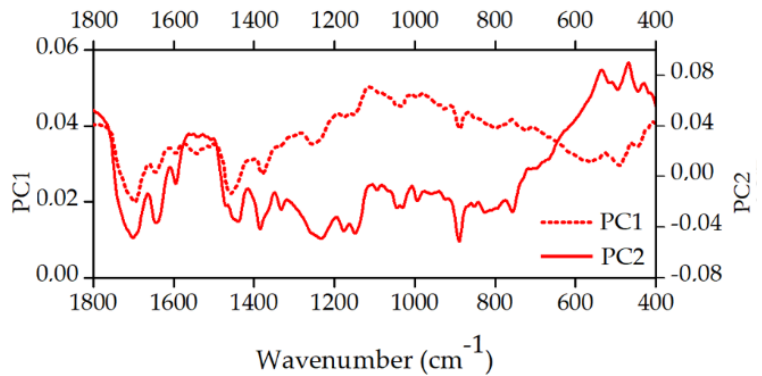

Figure 5. Score plots and loadings of the test with Velvesil TM Plus $(\mathbf{a}, \mathbf{b})$, water in agarose $(\mathbf{c}, \mathbf{d})$, and Tween $20(\mathbf{e}, \mathbf{f})$ are displayed. In the score plots, the application time is expressed in minutes by the labels. 
In the scores plot, four areas were recognizable, corresponding to the four quadrants. Spectra of the original varnished surface (grey stars) were placed in the first quadrant (I), where both PCs assume positive values. This resulted in being the quadrant in which the spectra of well-cleaned surfaces were better described. In this portion, the clean areas were supposed to be represented. On the opposite quadrant (III), where the PCs were both negative, the spectra corresponding to the soiled condition (the green square) were grouped. The II quadrant (PC1 negative-PC2 positive) assembled the spectra corresponding to a mild effect of the cleaning and a presumed presence of sweat. Finally, in the IV quadrant (PC1 positive-PC2 negative) of the scores plot, the spectra characterized by the presence of the residues of the Velvesil ${ }^{\mathrm{TM}}$ Plus were positioned, as already shown by the direct observation of the spectra. The distribution in the scores plot was supported by the loadings plot (Figure 5b); the range portions, where the PC1 showed high variability and assumed lower values, included the diagnostic bands of the soiling and the silicone residues. The presence of such a residue that could affect the distribution of the green squares and triangles in the second quadrant, could cover the effect of the cleaning. Under this scenario, the cleaning at 45 and 25 min could also be suitable.

As concerns the water in agarose and the Tween 20 cleaning tests, the PCA approach turned out to be powerful and fundamental to visualize the difference among the spectra that, by a preliminary visual approach, were all very similar to each other and little descriptive. In the new space described by PC1 and PC2, the variability of the spectra was well displayed and the discussion of the scores plot by the loadings could guide to a hypothesis very similar to those introduced by the colorimetric data analysis. In Figure 5c, which shows the scores plot of PCA (PC1 explaining 86.44\% and PC2 explaining $7.92 \%$ of the total variance) for the water in agarose test, both varnished and cleaned samples were characterized by a positive value of $\mathrm{PC} 2$, whereas soiled surfaces assumed negative values. Along the PC1, it was expected to distinguish spectra by the effect of the cleaning. However, due to the high but unavoidable variability of the surfaces, remarked by the position of the varnish cleaned surface (grey stars), circumspect considerations must be applied. Nonetheless, it is quite clear that cleaning effectiveness did not seems to depend on the application time. In particular, for the SSw area, the longest application times were close to the soiled reference (the blue square at time zero). A first mild effect could be recognized in $30 \mathrm{~min}$ exposure, whereas longer time seemed to spread the soiling without removing it. This is shown by the PC2 loadings (Figure 5d), characterized by a high contribution of soiling diagnostic bands around $500 \mathrm{~cm}^{-1}$. It means that for those spectra identified with a negative PC2, it was likely to strengthen the hypothesis that the soiling was not removed. In the case of the water in agarose, it was true for all the application times, suggesting the inadequacy of this method for both the chromatic and compositional features.

Tween 20 in agarose seemed to have a good effect in removing the soiling from the SSw area since the first application time; all the red squares in Figure 5e were very close to the grey stars, which represented the original varnished surface, and very far from the red square at zero time that described SSw. Despite the peculiar behavior being shown by the scores and the loadings plot for the spectra collected in the Sw, respectively in Figure $5 \mathrm{e}, \mathrm{f}$, they were grouped in a very positive PC1 (76.07\% explained variance) and in negative PC2 (13.81\% explained variance) area, except for the $90 \mathrm{~min}$ application time that could be considered an outlier. No relevant explanations drive this distribution, calling the need for further pre-processing approaches and variable selection strategies.

\section{Conclusions}

In this study, we investigated the removal of soiling from varnished surfaces using aqueous methods in gel and a silicone-based material. We demonstrated that the effectiveness of the cleaning procedures can be evaluated through the analysis of specific IR absorbance bands, related to the inorganic fraction of the soiling mixture, and through the Ca spatial distribution, detected by XRF mapping. We also highlighted the benefits of treating colorimetric and IR spectral datasets with a chemometric approach, i.e., PCA, demonstrating how the multivariate method allows a better explanation of the dynamics of the soiling removal. Variations in the intensity of the selected IR bands 
and in the Ca spatial distribution inferred that deionized water in agarose has a weak action in the soiling removal, whereas Tween $20(3 \%)$ in agarose and Velvesil ${ }^{\mathrm{TM}}$ Plus produced more remarkable effects.

For what concerns the use of deionized water in agarose, it is worth noting that its removal action was mild. Further, we did not observe an improvement of the chromatic features, probably due to the weak capability of the gel to remove dark matter particles. This issue let us infer that such a method is not suggested in the presence of a dark soiled surface. Better results could be expected with longer application times and this will be the object of further experimentation.

Regarding the Tween $20(3 \%)$ in agarose, we demonstrated that it was the most effective in removing the dark matter in the shortest time employed in this research (45 min). Nonetheless, we also observed that not all the soiling matter was removed even at the longest time (180 $\mathrm{min})$. In this case, the polar affinity coupled with the surfactant property of the solvent could be responsible for the removal action, revealing also the nature of the mixture soiling-sweat.

As regards the Velvesil ${ }^{\mathrm{TM}}$ Plus, its effectiveness was proved within the first $5 \mathrm{~min}$. A longer application time, 25 and $45 \mathrm{~min}$, could compromise the varnish and its properties. Nonetheless, PCA results warn about the reading of these data since the presence of the product residues could cover the information about the cleaning effect. Moreover, it was shown that its non-polar and surfactant nature could also probably play a role in sweat removal. Despite this first observation, the study of the interaction between the Tween 20 or the Velvesil ${ }^{\mathrm{TM}}$ Plus and the sweaty surface is still an open challenge that requires further investigation.

An outstanding result was represented by the PC1 loading being always positive for the spectral data. It is highly informative of the fact that is essential to go on with further data processing and manipulation, including, for instance, the reduction of the spectral range in specific areas of interest and a different pre-processing strategy, in order to enhance the tiny features that at the moment are hidden by the high similarity between the collected spectra. Above all, it is necessary to disclose the dynamics of the sweaty surface that was not possible to be deeply explained until now. In this perspective, further data processing is ongoing.

To conclude, for what concerns this step of the study, some practical outstanding results for the conservators and the restorers were gained mainly concerning the Velvesil ${ }^{\mathrm{TM}}$ Plus test: the presence of post-cleaning residues was demonstrated by the FTIR spectroscopy, the interaction with the resins of the historical varnish could be supposed in the case in which the soiling coat is missing; and the XRF maps showed a low accuracy in the selection of the area to be cleaned.

Author Contributions: Conceptualization, R.M., M.M., and M.A.; methodology, M.M. and M.A.; formal analysis, M.A. and S.G.; investigation, M.A., C.I., G.F., and T.R.; resources and laboratory materials, C.M.; data curation, M.A.; writing-original draft preparation, M.A.; writing—review and editing, G.F., C.I., T.R., and M.L.; visualization, M.A., S.G., and G.F.; supervision, M.M., D.C., and M.L.; and project administration, M.M. All authors have read and agreed to the published version of the manuscript.

Funding: This research received no external funding.

Acknowledgments: The authors would like to thank Bresciani S.r.l. for providing us with the Velvesil TM Plus and the Tween 20; likewise, the 4th year students of the degree course in Cultural heritage conservation and restoration for musical and scientific instruments of the University of Pavia for taking care of the preparation and the application of the historical varnish on the mock-ups.

Conflicts of Interest: The authors declare no conflict of interest.

\section{References}

1. Dillmann, P.; Watkinson, D.; Angelini, E.; Adriaens, A. Corrosion and Conservation of Cultural Heritage Metallic Artefacts; Woodhead Publishing Limited: Cambridge, UK, 2013.

2. Pozzi, G. Dizionario di Fisica e Chimica Applicate Alle Arti Secondo Le Dottrine Di Libes, Chaptal, Berthollet e Parkes e Giusta Le Teorie Moderne Ed i Metodi i Più Semplici, Introdottisi Nei Diversi Processi Chimici; Batelli e Fanfani: Milano, Italy, 1829.

3. Berzelius, J.J.; Jourdan, A.J.L.; Esslinger, M. Trattato Di Chimica; G. Antonelli: Venezia, Italy, 1830; pp. $496-497$. 
4. Bonanni, F. Trattato Sopra la Vernice Detta Comunemente Cinese; Per le Stampe di Lelio dalla Volpe con licenza de' Supervisori: Bologna, Italy, 1786.

5. Cremonesi, P. Materiali E Metodi Per La Pulitura Di Opere Policrome; PHASE: Firenze, Italy, 1997.

6. Carretti, E.; Dei, L.; Weiss, R.G.; Baglioni, P. A new class of gels for the conservation of painted surfaces. J. Cult. Herit. 2008, 9, 386-393. [CrossRef]

7. Doherty, T.; Stavroudis, C.; Hickey, J. Developing cleaning systems for water-sensitive paints by adjusting $\mathrm{pH}$ and conductivity. In Proceedings of the 39th Annual Meeting of the American Institute for Conservation and Historic Works (AIC Painting Specialty Group), Philadelphia, PA, USA, 31 May-3 June 2011.

8. Galatis, P.; Boyatzis, S.; Theodorakopoulos, C. Removal of a synthetic soiling mixture on mastic, shellac \& Laropal@K80 coatings using two hydrogels. e-Preserv. Sci. 2012, 9, 72-83.

9. Wolbers, R. Cleaning Painted Surfaces: Aqueous Methods; Archetype Pubns: London, UK, 2000.

10. Wolbers, R.; Bartolozzi, E. La Pulitura di Superfici Dipinte: Metodi Acquosi; Il Prato: Padova, Italy, 2005.

11. Cremonesi, P. Rigid Gels and Enzyme Cleaning in New Insights into the Cleaning of Paintings Proceedings from the Cleaning 2010 International Conference Universidad Politécnica de Valencia and Museum Conservation Institute; Marion, F., Mecklenburg, A., Charola, E., Robert, J., Eds.; Koestler: Washington, DC, USA, 2013; pp. 179-183. [CrossRef]

12. Keynan, D.; Hughes, A. Testing the Waters: New Technical Applications for the Cleaning of Acrylic Paint Films and Paper Supports. Book Paper Group Annu. 2013, 32, 43-51.

13. Sansonetti, A.; Bertasa, M.; Canevali, C.; Rabbolini, A.; Anzani, M.; Scalarone, D. A review in using agar gels for cleaning art surfaces. J. Cult. Herit. 2020, 41. [CrossRef]

14. Cremonesi, P. L'Uso di Tensioattivi e Chelanti nella Pulitura di Opere Policrome; Il Prato: Padova, Italy, 2001.

15. Cremonesi, P. L'Ambiente Acquoso per la Pulitura delle Opere Policrome; Il Prato: Padova, Italy, 2002.

16. Cremonesi, P. L'Uso dei Solventi Organici nella Pulitura di Opere Policrome; Il Prato: Padova, Italy, 2002.

17. Baglioni, P.; Berti, D.; Bonini, M.; Carretti, E.; Dei, L.; Fratini, E.; Giorgi, R. Micelle, microemulsions, and gels for the conservation of cultural heritage. Adv. Colloid Interfac. 2014, 205, 361-371. [CrossRef] [PubMed]

18. Baglioni, P.; Chelazzi, D.; Giorgi, R. Nanotechnologies in the Conservation of Cultural Heritage: A Compendium of Materials and Techniques; Springer: Berlin/Heidelberg, Germany, 2015.

19. Cremonesi, P. Proprietà ed Esempi di Utilizzo di Materiali Siliconici nel Restauro di Manufatti Artistici; Il Prato: Padova, Italy, 2016.

20. Stavroudis, C. More from CAPS3: Surfactants, silicone-based solvents, and microemulsions. Newsl. West. Assoc. Art Conserv. 2012, 34, 24-27.

21. Stavroudis, C. Silicone-based solvents in conservation. As free solvents and components of gel systems and microemulsions. In Atti del VII Congresso Internazionale Colore e Conservazione Dall'olio All'acrilico, Proceedings of Dall'impressionismo All'arte Contemporanea, Milano, Italy, 13-14 Novembre 2015; Il Prato: Padova, Italy, 2015.

22. Lagalante, A.; Wolbers, R. The cleaning of acrylic paintings: New particle-based water-in-oil emulsifiers. In Atti del VII Congresso Internazionale Colore e Conservazione Dall'olio All'acrilico, Proceedings of Dall'impressionismo All'arte Contemporanea, Milano, Italy, 13-14 Novembre 2015; Il Prato: Padova, Italy, 2015.

23. Lo Monaco, A.; Marabelli, M.; Pelosi, C.; Picchio, C. Colour measurements of surfaces to evaluate the restoration materials. In Proceedings of the O3A: Optics for Arts, Architecture, and Archaeology III Proceedings of a Meeting, Munich, Germany, 25-26 May 2011. [CrossRef]

24. Striova, J.; Salvadori, B.; Fontana, R.; Sansonetti, A.; Barucci, M.; Pampaloni, E.; Marconi, E.; Pezzati, L.; Colombini, M.P. Optical and spectroscopic tools for evaluating Er:YAG laser removal of shellac varnish. Stud. Conserv. 2015, 60 (Suppl. 1), S91-S96. [CrossRef]

25. Rovetta, T.; Invernizzi, C.; Fiocco, G.; Albano, M.; Licchelli, M.; Gulmini, M.; Alff, G.; Fabbri, D.; Rombolà, A.G.; Malagodi, M. The case of Antonio Stradivari 1718 ex-San Lorenzo violin: History, restorations and conservation perspectives. J. Archaeol. Sci. Rep. 2019, 23, 443-450. [CrossRef]

26. Ormsby, B.; Kampasakali, E.; Miliani, C.; Learner, T. An FTIR-based exploration of the effects of wet cleaning treatments on artists' acrylic emulsion paint films. e-Preserv. Sci. 2009, 6, 186-195.

27. Azémard, C.; Vieillescazes, C.; Ménager, M. Effect of photodegradation on the identification of natural varnishes by FT-IR spectroscopy. Microchem. J. 2014, 112, 137-149. [CrossRef]

28. Ciofini, D.; Striova, J.; Camaiti, M.; Siano, S. Photo-oxidative kinetics of solvent and oil-based terpenoid varnishes. Polym. Degrad. Stabil. 2016, 123, 47-61. [CrossRef] 
29. Invernizzi, C.; Daveri, A.; Vagnini, M.; Malagodi, M. Non-invasive identification of organic materials in historical stringed musical instruments by reflection infrared spectroscopy: A methodological approach. Anal. Bioanal. Chem. 2017, 409, 3281-3288. [CrossRef] [PubMed]

30. Invernizzi, C.; Fichera, G.V.; Licchelli, M.; Malagodi, M. A non-invasive stratigraphic study by reflection FT-IR spectroscopy and UV-induced fluorescence technique: The case of historical violins. Microchem. J. 2018, 138, 273-281. [CrossRef]

31. Albano, M.; Fiocco, G.; Invernizzi, C.; Licchelli, M.; Malagodi, M.; Marotti, R.; Merlo, C.; Rovetta, T.; Comelli, D. Cleaning of historical scientific instruments: First analytical studies. In Proceedings of the IMEKO Proceedings 2019, IMEKO TC-4 International Conference on Metrology for Archaeology and Cultural Heritage, Firenze, Italy, 4-6 December 2019; pp. 499-504.

32. Luciano, G.; Leardi, R.; Letardi, P. Principal component analysis of colour measurements of patinas and coating systems for outdoor bronze monuments. J. Cult. Herit. 2009, 10, 331-337. [CrossRef]

33. Manzano, E.; Navas, N.; Checa-moreno, R.; Rodriguez-simon, L.; Capitanvallvey, L.F. Preliminary study of UV ageing process of proteinaceous paint binder by FT-IR and principal component analysis. Talanta 2009, 77, 1724-1731. [CrossRef]

34. Alberghina, M.F.; Barraco, R.; Basile, S.; Brai, M.; Pellegrino, L.; Prestileo, F.; Schiavone, S.; Tranchina, L. Mosaic floors of roman Villa del Casale: Principal component analysis on spectrophotometric and colorimetric data. J. Cult. Herit. 2014, 15, 92-97. [CrossRef]

35. Fichera, G.; Rovetta, T.; Fiocco, G.; Alberti, G.; Invernizzi, C.; Licchelli, M.; Malagodi, M. Elemental analysis as statistical preliminary study of historical musical instruments. Microchem. J. 2018, 137, 309-317. [CrossRef]

36. Grassi, S.; Fiocco, G.; Invernizzi, C.; Rovetta, T.; Albano, M.; Davit, P.; Gulmini, M.; Stani, C.; Vaccari, L.; Licchelli, M.; et al. Managing complex Synchrotron radiation FTIR micro-spectra from historic bowed musical instruments by chemometrics. In Proceedings of the IMEKO 2019, IMEKO TC-4 International Conference on Metrology for Archaeology and Cultural Heritage, Firenze, Italy, 4-6 December 2019; pp. 114-119.

37. Wolbers, R. The use of a synthetic soiling mixture as a means for evaluating the efficacy of aqueous cleaning materials on painted surfaces. Conserv. Restaur. Biens Cult. Rev. l'ARAAFU 1992, 4, 22-29.

38. Campani, E.; Cremonesi, E.; Saccani, I.; Casoli, A.; Signorini, E. L'Uso di Agarosio e Agar per la Preparazione di "Gel Rigidi"; Il Prato: Padova, Italy, 2007; ISBN 888956665. 